\title{
Adverse immunological imprinting by cytomegalovirus sensitizing for allergic airway disease
}

\author{
Matthias J. Reddehase ${ }^{1}$ (D)
}

Received: 25 March 2019 / Accepted: 5 April 2019 / Published online: 10 May 2019

(c) Springer-Verlag GmbH Germany, part of Springer Nature 2019

\begin{abstract}
Cytomegalovirus (CMV) infection has a profound impact on the host's immune system. Immunological imprinting by CMV is not restricted to immunity against CMV itself, but can affect immunity against other viral or non-viral infectious agents and also immunopathological responses. One category is heterologous immunity based on molecular mimicry, where antigen recognition receptors specific for a CMV antigen with broad avidity distribution also bind with some avidity to unrelated antigens and exert effector functions against target structures other than those linked to CMV. Another category is induction of cytokines by CMV infection that inhibit or drive immune responses to bystander antigens unrelated to CMV, and a third category is the activation of antigen-presenting cells by CMV from which unrelated antigens profit as "stowaways". A striking example of the "stowaway" category, actually one that is of medical importance, has been published recently and will be discussed here for the more general reader. Specifically, in a murine model, CMV airway infection and inhaled environmental antigen of poor intrinsic allergenic potential were found to sensitize for allergic airway disease (AAD) only when combined. As to the mechanism, viral activation of $\mathrm{CD} 11 \mathrm{~b}^{+}$conventional dendritic cells $\left(\mathrm{CD} 11 \mathrm{~b}^{+} \mathrm{cDC}\right)$ that localize to airway mucosa facilitates uptake and processing of inhaled antigen. Thus, CMV serves as a "door opener" for otherwise harmless environmental antigens that have no intrinsic property to activate DC. Antigen-laden CD $11 \mathrm{~b}^{+} \mathrm{cDC}$ migrate selectively to the airway draining lymph nodes, where they prime type- $2 \mathrm{CD} 4^{+} \mathrm{T}$ helper (Th-2) cells. Upon airway re-exposure to the inhaled antigen, Th-2 cells secrete interleukins (IL-4, IL-5, IL-9, and IL-25) known to induce goblet cell metaplasia, the lead histopathological manifestation of $\mathrm{AAD}$ that is characterized by thickening of airway epithelia and increased numbers of mucus-producing goblet cells, resulting in enhanced mucus secretion and airflow obstruction.
\end{abstract}

Keywords Airways $\cdot$ Airway mucosa $\cdot$ Allergic airway disease (AAD) $\cdot$ Allergy $\cdot$ Antigen presentation $\cdot$ Asthma $\cdot$ Bronchial mucosa $\cdot \mathrm{CD}_{11} \mathrm{~b}^{+} \mathrm{cDC} \cdot$ Conventional dendritic cell(s) (cDC) Dendritic cell(s) (DC) Environmental antigen(s) $\cdot$ Goblet cell(s) (GC) · Goblet cell hyperplasia · Goblet cell metaplasia · IL-4 · IL-5 · IL-9 · IL-25 · Mucus · Mucus hypersecretion · Ovalbumin $\cdot$ Th-2 cells

Edited by: Stipan Jonjic.

This article is part of the Special Issue on Immunological Imprinting during Chronic Viral Infection.

Matthias J. Reddehase

Matthias.Reddehase@uni-mainz.de

1 Institute for Virology and Research Center for Immunotherapy (FZI), University Medical Center of the Johannes Gutenberg-University Mainz, Obere Zahlbacher Strasse 67, Hochhaus am Augustusplatz, 55131 Mainz, Germany

\section{Introduction: medical background}

Human cytomegalovirus (hCMV) is not a textbook example of a respiratory viral infection. Nonetheless, hCMV infection has a respiratory phase that usually is not diagnosed because of its mild and unspecific symptoms in the immunocompetent host. So, it is subsumed under the popular term "common cold" that is used for symptoms of respiratory virus infections for which there is no medical indication to identify the cause and for which symptomatic treatment is sufficient, for instance infections with rhinoviruses, common coronaviruses, and parainfluenza viruses. Historically, CMVs were named "salivary gland viruses" ([1, 2], reviewed in [3, 4]), as they replicate in acinar glandular epithelial cells of the salivary 
glands, from where they are released into the salivary duct [5, 6]. A frequent route of host-to-host transmission for primary infection is thus through saliva of a virus-shedding contact person, for instance in mother-to-child transmission. Transmission probability is increased whenever very young children crowd together, such as in multi-child families and in daycare centers. As an example of real life epidemiology for lectures on medicine, toy sharing, that is the mouthing of toys that other children have mouthed, has been identified as a way by which hCMV is transmitted between peers (reviewed in [7], see also the contribution by Adler and Reddehase in this issue of MMIM [8]).

With the saliva, virus reaches upper airway mucosas, where it replicates persistently for a prolonged period, and from there it also reaches lower airway mucosas in bronchi, bronchioli, and the lungs, as shown long ago and revisited more recently in murine models of intranasal infection using murine CMV (mCMV) $[9,10]$. This topic is specifically addressed and more comprehensively referenced by Zhang and colleagues in this issue of MMIM [11].

Children who undergo a primary airway infection after transmission of hCMV are unavoidably at the same time exposed to a universe of inhaled environmental antigens, few of which are classical allergens, whereas by far most have lowto-no intrinsic allergenic potential, as otherwise all of us would suffer from allergy. Clearly, allergic airway disease (AAD) elicited by inhaled environmental antigens is not the rule. The development of AAD requires a "sensitization phase", which, in immunological terminology, means "priming" of allergenspecific T cells, usually type- $2 \mathrm{CD}^{+}{ }^{+} \mathrm{T}$ helper (Th-2) cells, as well as re-exposure to the allergen for a recall response. In their effector phase, restimulated allergen-specific Th- 2 cells secrete cytokines that induce goblet cell (GC) metaplasia, such as the interleukins IL-4, IL-5, IL-9, and IL-25 [12-14]. Remodeling of the airway mucosa by transdifferentiation of ciliated cells and Clara/Club cells to mucus-producing GC, rather than by proliferation of GC [15], associated with thickening of airway epithelia and chronic mucus hypersecretion and consequent airflow obstruction, is the lead histopathological manifestation of AAD.

Mouse models, provided they are reasonably designed to meet a clinical correlate, have proven predictive value for human disease [16]. As airway exposure to environmental antigens at the time of primary airway infection after hCMV transmission is a realistic scenario of medical interest, recent work modeled this scenario in the mouse with the aim to investigate a possible virus-allergen interplay [17].

\section{Cytomegalovirus and low-potency allergen co-sensitize for AAD}

In the model (Fig. 1, top and [17]), immunocompetent C57BL/6 mice were simultaneously exposed via the airways to $\mathrm{mCMV}$ and to purified ovalbumin (OVA). OVA was chosen to represent a protein antigen that has low allergenic potential on its own and fails to sensitize for AAD. For tracking the fate of this low-potency allergen, OVA was tagged with a red fluorescent dye. On three consecutive days (days 14, 15, and 16) after sensitization, mice were re-exposed to OVA aerosol for a recall response, and airway histopathology was evaluated 2 days after the last challenge exposure (Fig. 1, histological images).

mCMV airway infection alone did not trigger AAD, nor did the combination of OVA-sensitization and OVA re-exposure. Combined sensitization by OVA and mCMV, however, followed by challenge exposures to OVA, caused AAD that is characterized by a massive increase in the number of mucus-producing GC. This histopathology is referred to in the literature as GC hyperplasia or metaplasia, depending on whether one focuses on the increase in GC numbers [12] or on the remodeling of the mucosa by transdifferentiation of ciliated cells and Clara/Club cells to GC [15], respectively. It should be noted that AAD was not induced when either OVA sensitization or OVA reexposure were missing. These controls verified the OVAspecificity of AAD. Depletion of $\mathrm{CD}^{+}{ }^{+} \mathrm{T}$ cells shortly before the first OVA challenge prevented AAD, whereas depletion of $\mathrm{CD}^{+} \mathrm{T}$ cells did not. So, the effector cells in AAD are OVA-specific $\mathrm{CD} 4^{+} \mathrm{T}$ cells.

\section{Cytomegalovirus supports a low-potency allergen in sensitizing for AAD by activation of migratory dendritic cells}

Based on the data by Reuter et al. [17], Fig. 2 provides a graphical summary that illustrates the mechanism by which mCMV imprints the immune system for AAD immunopathology. Upon co-exposure of airway mucosa to inhaled antigen/low potency allergen, represented by OVA in the specific case, and mCMV, the virus activates MHC-II ${ }^{+} \mathrm{CD} 11 \mathrm{c}^{+}$dendritic cells (DC) that localize to the mucosa, specifically DC of the CD $11 b^{+}$subset of conventional B220 ${ }^{\text {low }} \mathrm{Ly} 6 \mathrm{c}^{\text {low }} \mathrm{DC}$, briefly CD $11 \mathrm{~b}^{+} \mathrm{cDC}$. Their activation is indicated by upregulation of CD28 ligands $\mathrm{CD} 80$ and CD86, and is associated with enhanced uptake of OVA. The OVA-laden CD $11 b^{+}$cDC then migrate selectively to the airway draining lymph nodes, where they present processed OVA peptides by MHC-II molecules to 
Fig. 1 Coincident airway exposure to CMV and antigen sensitizes for AAD. Top Experimental protocol and time schedule. OVA-tagged Ovalbumin, fluorochromeconjugated with Alexa Fluor 647 for red fluorescence. Lower panels Histological images of bronchial mucosa tissue sections stained by Periodic Acid Schiff (PAS) combined with hematoxylin/eosin (HE). GC goblet cells stained in red. Bar marker: $25 \mu \mathrm{m}$, applying to all images. Based on the work by Reuter et al. (2019) [17], with new graphical arrangement and using new tissue sections from stored specimens. Histological images courtesy of J. Podlech, Institute for Virology, Mainz

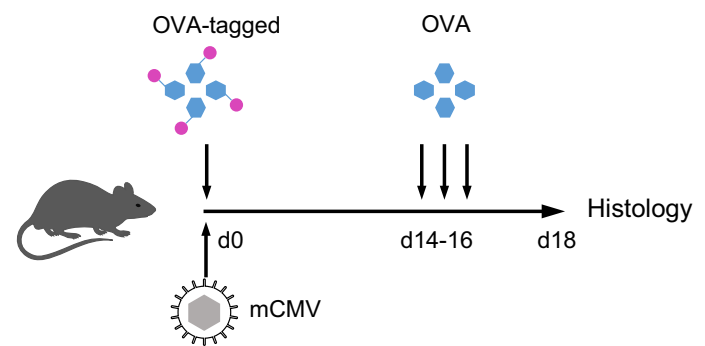

Sensitization Re-exposure Bronchial Mucosa

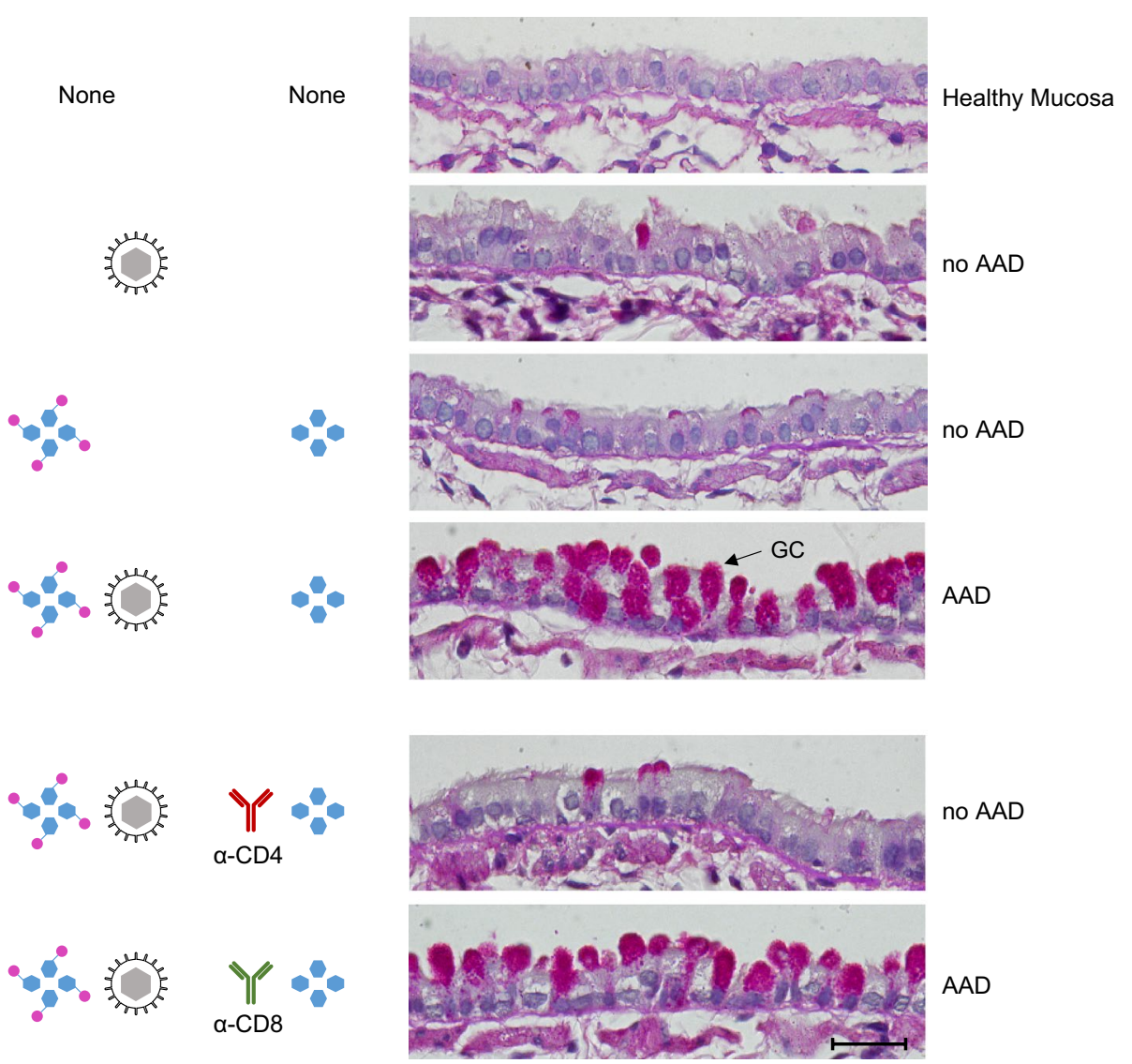

naïve OVA peptide-specific Th-2 cells for priming. Upon re-exposure to inhaled OVA, restimulated OVA peptidespecific Th- 2 cells secrete effector cytokines IL-4, IL-5, IL-9, and IL-25, all known to be involved in the induction of GC metaplasia.

\section{Résumé and outlook}

In essence, the work by Reuter and colleagues [17] has shown that the key event in sensitization for AAD is the efficient uptake and processing of an inhaled antigen by migratory DC that localize to the airway mucosa as sentinels. Classical allergens and most pathogens have the intrinsic property to activate $\mathrm{DC}$, whereas inhaled environmental protein antigens do not, and are thus ignored by the sentinels. This is a "healthy ignorance", as otherwise all environmental antigens would cause allergy. Activation of DC by CMVs is beneficial for priming a protective antiviral immune response, though it can result in allergic disease when used by otherwise harmless "stowaways" for entering DC. The findings suggests that by this "door opener" function, CMV airway infection may broaden the spectrum of potential allergens. Current experimental protocols did not lead to full-blown asthma. Future work will address the question if repetitive allergen exposure will eventually lead to clinical asthma.

Another interesting aspect for future research is the finding that AAD in the here discussed model was not accompanied by eosinophilia [17], unlike in established 


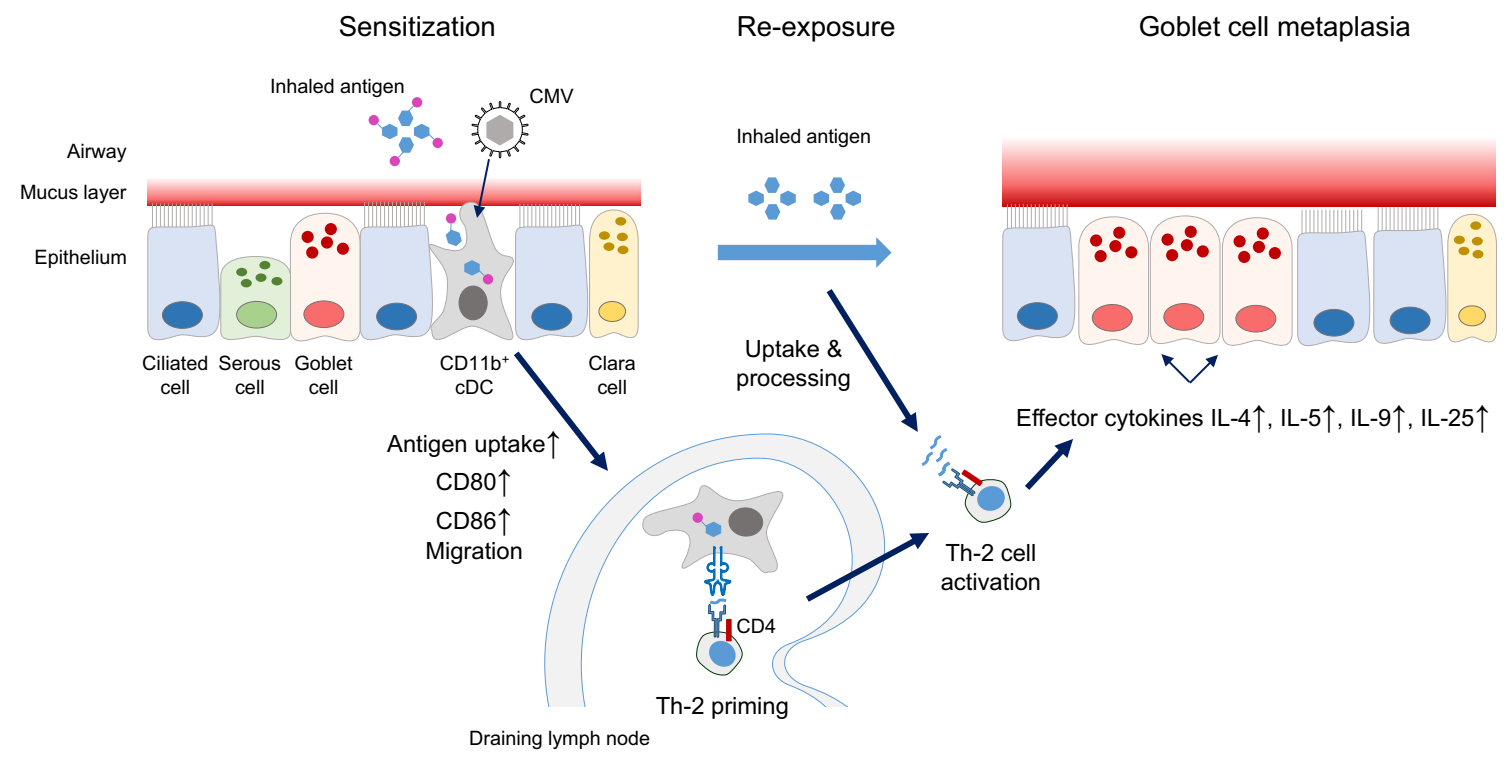

Fig. 2 Graphical abstract of the mechanism that leads to AAD/GC metaplasia. For detailed explanation, see the body of the text. The waved symbol represents peptide(s) derived by antigen processing.

$\mathrm{AAD} / \mathrm{asthma}$ mouse models and in most clinical forms of asthma. So, is it a bad model? Interestingly, there exists a clinical correlate, namely an asthma phenotype in humans known as non-eosinophilic asthma (NEA). NEA accounts for particularly severe cases of asthma, and its most relevant clinical trait is its poor response to asthma treatment with corticosteroids [18]. Testing if non-eosinophilic AAD, reviewed here and described in greater detail in [17], qualifies as a model, or can be developed into a model, for clinical NEA is therefore of top priority.

Acknowledgements MJR is supported by the Deutsche Forschungsgemeinschaft SFB 1292, individual project TP11.

\section{Compliance with ethical standards}

Conflict of interest The author declares that he has no conflict of interest.

\section{References}

1. Smith MG (1954) Propagation of salivary gland virus of the mouse in tissue cultures. Proc Soc Exp Biol Med 86:435-440

2. Smith MG (1956) Propagation in tissue cultures of a cytopathogenic virus from human salivary gland virus (SGV) disease. Proc Soc Exp Biol Med 92:424-430 $c D C$ conventional dendritic cell. The graphics concerning the airway mucosa was inspired by artwork presented in [12]

3. Ho M (2008) The history of cytomegalovirus and its diseases. Med Microbiol Immunol 197:65-73. https://doi.org/10.1007/ s00430-007-0066-x

4. Reddehase MJ (2015) Margaret Gladys Smith, mother of cytomegalovirus: 60th anniversary of cytomegalovirus isolation. Med Microbiol Immunol 204:239-241. https://doi.org/10.1007/ s00430-015-0416-Z

5. Henson D, Strano AJ (1972) Mouse cytomegalovirus. Necrosis of infected and morphologically normal submaxillary gland acinar cells during termination of chronic infection. Am J Pathol 68:183-202

6. Jonjić S, Mutter W, Weiland F, Reddehase MJ, Koszinowski UH (1989) Site-restricted persistent cytomegalovirus infection after selective long-term depletion of $\mathrm{CD}^{4+} \mathrm{T}$ lymphocytes. $\mathrm{J}$ Exp Med 169:1199-1212

7. Cannon MJ, Grosse SD, Fowler KB (2013) The epidemiology and public health impact of congenital cytomegalovirus infection. In: Reddehase MJ (ed) Cytomegaloviruses: from molecular pathogenesis to intervention, vol II. Caister Academic Press, Norfolk, pp 26-48

8. Adler SP, Reddehase MJ (2019) Pediatric roots of cytomegalovirus recurrence and memory inflation in the elderly. Med Microbiol Immunol. https://doi.org/10.1007/s00430-019-00609-6

9. Jordan MC (1978) Interstitial pneumonia and subclinical infection after intranasal inoculation of murine cytomegalovirus. Infect Immun 21:275-280

10. Oduro JD, Redeker A, Lemmermann NA, Ebermann L, Marandu TF, Dekhtiarenko I, Holzki JK, Busch DH, Arens R, Čičin-Šain L (2016) Murine cytomegalovirus (CMV) infection via the intranasal route offers a robust model of immunity upon mucosal CMV infection. J Gen Virol 97:185-195. https://doi. org/10.1099/jgv.0.000339 
11. Zhang S, Caldeira-Dantas S, Smith CJ, Snyder CM (2019) Persistent viral replication and the development of T-cell responses after intranasal infection by MCMV. Med Microbiol Immunol. https:// doi.org/10.1007/s00430-019-00589-7

12. Rogers DF (2002) Airway goblet cell hyperplasia in asthma: hypersecretory and anti-inflammatory? Clin Exp Allergy 32:1124-1127

13. Barnes PJ (2008) The cytokine network in asthma and chronic obstructive pulmonary disease. J Clin Invest. 118:3546-3556. https://doi.org/10.1172/JCI36130

14. Finkelman FD, Hogan SP, Hershey GK, Rothenberg ME, WillsKarp M (2010) Importance of cytokines in murine allergic airway disease and human asthma. J Immunol. 184:1663-1674. https:// doi.org/10.4049/jimmunol.0902185

15. Lambrecht BN, Hammad H (2012) The airway epithelium in asthma. Nat Med 18:684-692. https://doi.org/10.1038/nm.2737

16. Reddehase MJ, Lemmermann NA (2018) Mouse model of cytomegalovirus disease and immunotherapy in the immunocompromised host: predictions for medical translation that survived the "test of time". Viruses 10:e693. https://doi. org/10.3390/v10120693

17. Reuter S, Lemmermann NAW, Maxeiner J, Podlech J, Beckert H, Freitag K, Teschner D, Ries F, Taube C, Buhl R, Reddehase MJ, Holtappels R (2019) Coincident airway exposure to low-potency allergen and cytomegalovirus sensitizes for allergic airway disease by viral activation of migratory dendritic cells. PLoS Pathog 15:e1007595. https://doi.org/10.1371/journal.ppat.1007595

18. Esteban-Gorgojo I, Antolín-Amérigo D, Domínguez-Ortega J, Quirce S (2018) Non-eosinophilic asthma: current perspectives. J Asthma Allergy. 11:267-281. https://doi.org/10.2147/JAA.s1530 97

Publisher's Note Springer Nature remains neutral with regard to jurisdictional claims in published maps and institutional affiliations. 